\title{
Dynamical Models of Interactions between Herds Forage and Water Resources in Sahelian Region
}

\author{
Jean Jules Tewa, ${ }^{1}$ Alassane Bah, ${ }^{2}$ and Suares Clovis Oukouomi Noutchie ${ }^{3}$ \\ ${ }^{1}$ Department of Mathematics and Physics, National Advanced School of Engineering, University of Yaoundé I, \\ UMMISCO Team, Project GRIMCAPE, LIRIMA, Yaoundé, Cameroon \\ ${ }^{2}$ Université Cheikh Anta Diop de Dakar, Ecole Supérieure Polytechnique, UMMISCO, 5085 Dakar, Senegal \\ ${ }^{3}$ MaSIM Focus Area, North-West University, Mafikeng Campus, Mafikeng 2735, South Africa \\ Correspondence should be addressed to Suares Clovis Oukouomi Noutchie; 23238917@nwu.ac.za
}

Received 30 May 2014; Accepted 3 July 2014; Published 22 July 2014

Academic Editor: Abdon Atangana

Copyright (c) 2014 Jean Jules Tewa et al. This is an open access article distributed under the Creative Commons Attribution License, which permits unrestricted use, distribution, and reproduction in any medium, provided the original work is properly cited.

Optimal foraging is one of the capital topics nowadays in Sahelian region. The vast majority of feed consumed by ruminants in Sahelian region is still formed by natural pastures. Pastoral constraints are the high variability of available forage and drinking water in space and especially in time (highly seasonal, interannual variability) and the scarcity of water resources. The mobility is the main functional and opportunistic adaptation to these constraints. Our goal in this paper is to formalize two dynamical models for interactions between a herd of domesticate animals, forage resources, and water resources inside a given Sahelian area, in order to confirm, explain, and predict by mathematical models some observations about pastoralism in Sahelian region. These models in some contexts can be similar to predator-prey models as forage and water resources can be considered as preys and herd's animals as predators. These models exhibit very rich dynamics, since it predicts abrupt changes in consumer behaviour and disponibility of forage or water resources. The dynamics exhibits a possible coexistence between herd, resources, and water with alternative peaks in their trajectories.

\section{Introduction}

It is well known that pastoralism is the name given to the subsistence practice in which people care for and domesticate animals, usually ungulates such as camels, cattle, reindeer, sheep, and goats [1].

Pastoralism will continue for the near future in poor nations [2-4], especially in Africa, because it is generally an efficient, low energy requiring subsistence base for semiarid regions. During the 20th century, however, most national governments tried to force pastoralists to stop their migrations and to reduce the size of their herds in order to prevent overgrazing. These efforts at controlling them were consistently resisted by pastoralists. They usually saw large herds as symbols of wealth and as security against unpredictable climates and periodic epidemics among their animals [5].

Livestock in the Sahel is now basically a usurper such as land use regarding the vegetation that grows there naturally. The pastoral farming systems are those in which more than
$90 \%$ of the dry matter consumed by livestock comes from grazing. The researchers focus in this paper on these pastoralfarming systems. The transition from one system to another is periodic and depends on climate and economic context [6]. Part of pastoral population in the rural population varies greatly from country to country. Livestock numbers are not known with precision, because large part of statistics does not differentiate production systems. Based on national statistics, thus including agricultural areas, small ruminants are the most numerous, before cattle. Animal density can only be determined on well-defined regions, for which there are the number of both animals and areas used by livestock. The data always differ by authors.

The pastoral system is moving towards a systems approach mixed crop-livestock farming. This trend goes in North Africa with the grazing of steppe. In the Sahel, the environmental consequences are less obvious $[2,7,8]$. The vast majority of feed consumed by ruminants in Sahelian region is still formed by natural pastures. Savannas, steppes, and training fallow provide the basis of livestock feed, even 
in sedentary farming or being intensified. It is important to evaluate or to monitor their progress $[1,6]$.

There have been many problems about pastoral livelihood vulnerability. The dry lands cannot support sustained and reliable agriculture because of low and variable rainfall and high temperatures. Pastoralism, however, is extremely well suited to this type of environment. Pastoralists make optimum use of the dry lands by practicing a mobile and extensive livestock-keeping system. They move according to where and when fodder becomes available and use different herd management strategies such as herd splitting, herd diversification, and herd maximization to ensure that they spread the risk of livestock loss from droughts, diseases, and theft. All the while, they make maximum use of the available vegetation without degrading the environment [1].

Different explanations have been advanced for the increasing vulnerability of pastoralists. Population growth in pastoral areas has created pressure on land. Climate change has increased the frequency of droughts, floods, and livestock diseases. However, these natural factors only exacerbate the effects of a harsh policy and legal environment that is focused on "modernizing" and settling pastoralists. The increased vulnerability of pastoral livelihoods to shocks and other drivers of change are in many ways a function of the cumulative effect of these policies [1].

Long-term sustainable pastoral development requires a good knowledge of the dynamics of multiple factors underlining pastoralism and here research has a crucial role to play. Alongside support to improve primary and secondary education is the need to strengthen institutions of higher learning and research in pastoral areas of Africa [5]. Such institutions require support to conduct research on a range of political, social, and natural science subjects and at levels, which range from local adaptation to regional integration and global trends. The links between research and policy also need to be strengthened, so that policy responds to the dynamics of pastoral livelihoods in an efficient manner [5]. This paper is our contribution to this research in pastoral areas of Africa.

\section{Model Construction}

In Africa, the Sahel has a wet season (June to October) and a dry season (November to May) which are very distinct, and livestock is greatly influenced by the amount of grass and shrubs. As we said previously, more than $90 \%$ of dry matter consumed by livestock comes from grazing. Some problems as overgrazing or scarcity of water are frequently observed. These problems force some pastoralists to migrate with their herd. According to these facts, the intrinsic production of forage resources can be a negative number, even the intrinsic disponibility of water resources. The intrinsic production $r$ of forage resources can be written as $r=r_{0}-r_{1}$, where $r_{0}=r_{01} p+r_{02}$ as given in [8], $p$ denotes the precipitation, $r_{02}$ is the growth rate of the grasses and others without precipitation, and $r_{1}$ is the disappearing rate due to many reasons (competition, respiration, and human harvesting) different from herd's nutrition. The particularity of this model, which is the difference with classic predator-prey models in the literature, is the fact that the intrinsic production rate can be negative $(r<0)$. This situation is frequently observed in Sub-Saharan Africa, particularly in Sahelian region when precipitations are scarce. Intensification of this situation can conduct pastoralists to migrate with their herds: this is the transhumance. We also know [9] that tropical livestock unit (TLU) is a basic criterion for a head of cattle weighing $250 \mathrm{~kg}$. The daily volume of consumption of dry matter per TLU amounted to $6.5 \mathrm{~kg}$. However, since this criterion varies, there is obviously the case with differences depending on the country, even within each country. The test described here is also currently used officially by the Ministry of Agriculture and Livestock in Niger [9].

Parameter $K$ denotes the maximal number of livestock in this paper. When considering the question of the number of livestock that can be raised on a given surface, it is first important to know the amount of forage needed for livestock. To calculate the volume needed to feed livestock, measured by the volume of solids, the amount of assimilation of dry materials by livestock is generally estimated to be approximately $1.4 \%$ to $3.0 \%$ of the weight of livestock. In the Sahelian region, by experience, the following values are generally used on the basis of tropical livestock unit, in order to compute the daily volume of required dry matter per head [9].

One cattle: $5.2 \mathrm{~kg}[6.5 \mathrm{~kg}(\mathrm{TLU}) \times 0.8$ (index of the considered space)]. Two goats and sheep: $1.0 \mathrm{~kg}$ [6.5 kg $(\mathrm{TLU}) \times 0.15$ (index of the considered space)]. We can calculate the number of heads that can be raised with the formula below [9]. Rearing capacity $=[$ (volume of feed supply of natural grassland $\times$ utilization rate) divided by (daily volume required per capita solids) $] \times$ number of days of reliance on natural grassland.

Let us give some hypotheses concerning the models in this paper.

(H1) The herds, forage, and water resources considered in this paper are in the same area.

(H2) When the intrinsic production is nonnegative, if feed resources are not consumed, they change their amount to the maximal production capacity and therefore storage. In this case the feed resources grow logistically. When the intrinsic production is negative, the feed resources will disappear at long time, and this situation conducts pastoralists to migrate with their herds: this corresponds to the transhumance situation.

(H3) If the herd is helpless, its number of animals or its tropical livestock unit (TLU) decreases and may disappear if nothing is done.

(H4) Interactions between the herd and forage resources are following the functional response of MichaelisMenten or Holling function response of type II.

(H5) Consumption of resources has an instant effect on the reduction of forage resources and increased biomass of the herd, in proportion to their consumption.

In the study of interactions between herds, forage, and water resources, it is crucial to determine which specific form of functional response, describing the amount of 
resources consumed by an animal in the herd per unit time, is ecologically plausible and provides a solid basis for theoretical development. As in [11-13], density dependence of the resources will be the starting point, which gives a functional response. In the simplest case, such a function is a linear function of the forage resources density $(R)$, which is integrated into the classic Lotka-Volterra model. The linear functional response is a limited case and can only be seen over a short period. But one can use the Michaelis-Menten or Holling response function of type II defined by $\phi(R)=$ $\left(B \omega_{0} R /\left(1+B \omega_{1} R\right)\right)$, where $R$ denotes the forage resources density, $\omega_{0}$ and $\omega_{1}$ denote, respectively, the time taken by a herd's animal to search and consume forage resources, and $B$ is the herd consumption rate per unit of time. With the Holling function response of type II, it is well known that the diminution of forage resources due to the herd consumption increases and the forage density decreases and becomes constant at the end. In the model formulated here, $\gamma$ is the removal rate from the herd (death, off take...); parameter $e$ denotes the conversion rate of the forage resources consumed by the herd's animals into their biomass. When there is no herd, the dynamics of forage resources can be governed by the logistic equation, but the intrinsic production can be negative, such that $(0,0)$ is a stable equilibrium. Setting $H(t)$ as the tropical livestock unit of the herd at day $t$, the function $g(R, H)=B \omega_{0} R(t) H(t) /\left(1+B \omega_{1} R(t)\right)$ can also be written as $g(R, H)=q R(t) H(t) /(1+a R(t))$, where $q=B \omega_{0}$ denotes the utilization rate of forage resources and $a=B \omega_{1}$ denotes the satiety rate of herd's animals. The following differential equations model interactions between forage resources and animals of the herd:

$$
\begin{gathered}
\frac{d R(t)}{d t}=\left(r_{01} p+r_{02}-r_{1}\right)\left(1-\frac{R}{K}\right) R-\frac{q R H}{1+a R}, \\
\frac{d H(t)}{d t}=e \frac{q R H}{1+a R}-\gamma H .
\end{gathered}
$$

According to a study conducted by the Japan Green Resources Corporation (JGRC) [9], in a region where the average annual precipitation is $500-600 \mathrm{~mm}$, the volume of dry matter production of grass per hectare in natural grassland was in tons 1.54 in 1997, 1.6 in 1998, and 1.8 in 1999 (according to research conducted on mowing in October each year). Among wild herbs growing in this region are the grasses that cattle prefer, but they also appreciate the taste of some legumes.

Until now, in many cases (excluding reservoir dams) small artificial wells and natural ponds were used to supply livestock with drinking water. In all these cases, the storage capacity of water is low, and we find ourselves in a situation of chronic lack of water during the dry season. In addition, the storage capacity of water ponds in some places decreases by the reduction of vegetation in the water accumulation area and the influx of land in the ponds. There is sometimes also conflict when cattle in two villages must share the same drinking water source [9]. It is well known that it is not easy to get water in Sahelian region. For sustainable use of water sources that are ponds, it is also necessary to take a measure of water conservation preventing the influx sand around ponds. For example, one study of the Japan Green Resources Corporation showed that establishment of lines of stones can retain the sand and promote the restoration of wild vegetation. The earth is accumulating inside line of stones (the side from which comes the influx); the storage capacity of water becomes higher and ability to grow fodder crops and planting fodder trees becomes larger. This allows obtaining fodder and shade for livestock, and it becomes possible to revive the natural clam that was impoverished around the pond, as a grazing area including a watering place for the cattle [9].

The pool of Eda (which is straddled between the villages of Magou and Eda in Niger) had long been used as a point of watering the cattle moving to the Burkina Faso, but due to the decrease in its subsequent storage capacity of water to the influx of sand in the pool, it could not provide the volume of water required to move livestock and livestock of the two villages. But thanks to the digging of the pond and the establishment of lines of stones (some with citizen participation), the revegetation of weeds is increasing, and livestock numbers even greater than in the past are not gathering [10].

The variable $H(t)$ is the tropical livestock unit of the herd at time $t, R(t)$ is the forage resources density (kilograms of dry matter per hectare) at time $t, W(t)$ denotes the water resources at time $t, m$ is the removal rate from the herd, $e_{1}$ is the conversing rate of forage resources consumed into herd biomass, and $e_{2}$ is the conversing rate of water resources consumed into herd biomass; as previously, $r_{1}=r_{01}^{1} p+$ $r_{02}^{1}-r_{1}^{1}$ is the intrinsic production of forage resources and $r_{1}=r_{01}^{2} p+r_{02}^{2}-r_{1}^{2}$ the intrinsic disponibility of water; $p$ is the precipitation rate in the area; $K_{1}$ is the maximal capacity of the considered area to support forage resources; $K_{2}$ is the maximal capacity of the area to contain large quantity of water; $q_{1}$ and $q_{2}$ are, respectively, the utilization rates of forage and water resources.

Following [14, 15], we set $q_{i}=\left(\omega_{0 i} / \omega_{1 i}\right)$ and $a_{i}=\left(1 / B \omega_{1 i}\right)$. The dynamical model for interactions between herds, forage resources, and water is given by the following system of differential equations:

$$
\begin{gathered}
\frac{d R}{d t}=\left(r_{01}^{1} p+r_{02}^{1}-r_{1}^{1}\right)\left(1-\frac{R}{K_{1}}\right) R-\frac{q_{1} R H}{a_{1}+R}, \\
\frac{d W}{d t}=\left(r_{01}^{2} p+r_{02}^{2}-r_{1}^{2}\right)\left(1-\frac{W}{K_{2}}\right) W-\frac{q_{2} W H}{a_{2}+W}, \\
\frac{d H}{d t}=-m H+e_{1} \frac{q_{1} R H}{a_{1}+R}+e_{2} \frac{q_{2} W H}{a_{2}+W} .
\end{gathered}
$$

We therefore have three trophic levels: one predator and two preys. The intrinsic production rates $r_{1}$ and $r_{2}$ defined, as previously, can be negative values. In the absence of forage and water resources $\left(r_{1}<0\right.$ and $\left.r_{2}<0\right)$, the herd is doomed if nothing is done. In this case, pastoralists will migrate with their herds (transhumance). Its workforce decreases and goes to extinction if nothing is done. But, in the absence of the herd, forage resources are stored and accumulate until the limit capacity when $r_{1}>0$; forage resources can disappear when $r_{1}<0$. The water resources can accumulate to exceed the carrying capacity, but it will very quickly go back to limit 
capacity when $r_{2}>0$; water resources can disappear when $r_{2}<0$.

Let us give now a mathematical analysis of System (1) and interpretations of the results in terms of pastoralism, using the data [10].

\section{Mathematical Results and Interpretations in Sahelian Context}

\subsection{Results of System (1)}

Lemma 1. The nonnegative orthant $I R_{+}^{2}$ is positively invariant by the trajectories of System (1), and the set $D=\{(R, H) \in$ $\left.I R_{+}^{2} / R \leq K\right\}$ is a compact forward and absorbing set for System (1).

Remark 2. This theorem confirms the fact that forage resources quantity and the number of animals in the herd are always nonnegative numbers, since their trajectories are always in $I R_{+}^{2}$. Moreover, the forage resources quantity is bounded. This is ecologically plausible since temperatures are usually high and the stockage capacity is limited.

Lemma 3. The sign of the intrinsic production $r$ has an incidence on the dynamics of forage resources and then on the dynamics of the herd's animals.

(1) If $r>0$, then the forage resources converge to the maximal number of livestock $K$ for a long time.

(2) If $r<0$, then the forage resources will disappear for a long time if nothing is done. This situation conducts to the transhumance of pastoralists with their herds.

Lemma 4. Much equilibrium exists for System (1).

(1) Equilibrium $E_{0}=(0,0)$ and equilibrium $E_{1}=(K, 0)$ exist without any condition.

(2) When $r>0, E_{2}=\left(R^{*}, H^{*}\right)=(\gamma /(e q-a \gamma)$; $\left.(r / q)\left(1+a R^{*}\right)\left(1-\left(R^{*} / K\right)\right)\right)$ is an ecologically acceptable equilibrium if eq $>$ a $\gamma$ and the threshold $R_{1}=$ $(e q K / \gamma(1+a K))$ is such that $R_{1} \geq 1$. Therefore, with these conditions satisfied, there are three equilibria for System (1).

(3) When $r<0, E_{2}=\left(R^{*}, H^{*}\right)=((\gamma /(e q-$ a $\left.)) ;(r / q)\left(1+a R^{*}\right)\left(1-\left(R^{*} / K\right)\right)\right)$ is an ecologically acceptable equilibrium if eq $>$ a $\gamma$ and the threshold $R_{1}=(e q K / \gamma(1+a K))$ is such that $R_{1}<1$. Therefore, with these conditions satisfied, there are three equilibria for System (1).

Theorem 5. The following properties hold concerning System (1).

(1) The equilibrium $E_{0}$ is a saddle-node when $r>0$ and $a$ stable node when $r<0$.

(2) If $r>0, E_{1}$ is a globally asymptotically stable node when $R_{1}<1$ and a saddle-node with stability for forage resources and instability for herds when $R_{1}>1$.
If $r<0, E_{1}$ is a saddle-node when $R_{1}<1$ and $a$ locally unstable node when $R_{1}>1 . E_{1}$ is a globally asymptotically stable node when $R_{1}=1$. The centre manifold in this case is given by $W^{c}=\{x=h(y)$ : $\left.h(0)=K, h^{\prime}(0)=a_{1}\right\}$, where $h(y)=K+a_{1} y+a_{2} y^{2}+$ $O\left(y^{3}\right), a_{1}=-(q K / r(1+a K)), a_{2}=-\left(a_{1}^{2}(2 r a+((r+\right.$ $\left.\gamma) / K))+q a_{1} / r(1+a K)\right)$.

(3) The equilibrium $E_{2}$ is not ecologically acceptable when $R_{1}<1$. If $1<R_{1} \leq 1+(e q / a \gamma(1+a K))$, then $E_{2}$ is a globally asymptotically stable focus and when $R_{1}>$ $1+(e q / a \gamma(1+a K)), E_{2}$ is an unstable focus and there exists a limit cycle for System (1). This phenomenon corresponds to supercritical Hopf bifurcation [16].

Remark 6. The stability of equilibrium $E_{0}=(0,0)$ means that there will be no more forage resources and no animal of the herd in the considered area for a long moment. There can be many explanations to this situation. Droughts can cause animals mortalities through starvation, emergency slaughtering, and sales, or definitive herds migrations (transhumance), which can create severe drops in the herd sizes. The Sahelian region is particularly affected by such climate shocks [17]. Droughts can also cause forages' disappearance, and then the equilibrium $E_{0}$ is stable. When this removal concerns only animals of the herd, depending on some climatic changes, the forage resources growth towards the maximal quantity needed for livestock and the equilibrium $E_{1}=(K, 0)$ is stable. Concerning the coexisting equilibrium $E_{2}=\left(R^{*}, H^{*}\right)$, there is a Hopf bifurcation. The pastoral interpretation of Hopf bifurcation is that animals in the herd will coexist with the forage resources, exhibiting oscillatory balance behavior. We have a peak for the herd trajectory, followed by a peak for forage trajectory.

Theorem 7. Stability of $E_{1}$ and $E_{2}$

(1) If $1<R_{1} \leq 1+(e q / a \gamma(1+a K))$, then $E_{2}$ is a globally asymptotically stable focus when $r>0$ and an unstable focus when $r<0$.

(2) If $R_{1}>1+(e q / a \gamma(1+a K))$, then $E_{2}$ is an unstable focus when $r>0$ and a globally asymptotically stable focus when $r<0$.

(3) If $R_{1}=1+(e q / a \gamma(1+a K))$, then $E_{2}$ is a center point, with neutral stability.

(4) If $R_{1}<1$, then $E_{1}$ is a globally asymptotically stable node when $r>0$.

(5) If $R_{1}>1$, then $E_{1}$ is an unstable saddle-node when $r>0$ and equilibrium $E_{2}$ exists.

(6) If $R_{1}=1$, then $E_{1}$ is a globally asymptotically stable node when $r>0$ and just a locally asymptotically stable node when $r<0$.

Remark 8 (Hopf bifurcation). There is a limit cycle when $R_{1}$ passes through the value $1+(e q / a \gamma(1+a K))$. This phenomenon is known as Hopf bifurcation. Since the limit cycle is stable, it is a supercritical Hopf bifurcation. The pastoral interpretation of Hopf bifurcation as we said is that 
TABLE 1: Parameter values for transhumance in System (1).

\begin{tabular}{|c|c|c|c|}
\hline Parameters & Description & Estimated value/range & Reference \\
\hline$r_{01}$ & Intrinsic production coefficient & 10-20 kgDM/ha & [9] \\
\hline$r_{02}$ & Intrinsic production without precipitations & $5-10 \mathrm{kgDM} / \mathrm{ha}$ & [9] \\
\hline$p$ & Precipitations & $500-600 \mathrm{~mm} / \mathrm{yr}$ & [9] \\
\hline$r_{1}$ & Intrinsic disappearance of forage resources & $90-120 \mathrm{kgDM} / \mathrm{ha}$ & {$[9]$} \\
\hline$e$ & Forage biomass conversion rate & 0.015 per day & {$[10]$} \\
\hline$a$ & Herd's satiety rate & $0.01 / \mathrm{ha}$ & {$[10]$} \\
\hline$K$ & Maximal capacity of forage production & $500-600 \mathrm{kgDM} / \mathrm{ha}$ & {$[10]$} \\
\hline$q$ & Utilization rate of forage resources & 0.4 per day & {$[9]$} \\
\hline$\gamma$ & Removal rate in the herd & 1.0 per day & {$[10]$} \\
\hline
\end{tabular}

TABLE 2: Parameter values for transhumance in System (2).

\begin{tabular}{|c|c|c|c|}
\hline Parameters & Description & Estimated value/range & Reference \\
\hline$r_{01}{ }^{1}$ & Intrinsic production of forage & $10-20 \mathrm{kgDM} / \mathrm{ha}$ & [9] \\
\hline$r_{01}{ }^{2}$ & Intrinsic production of water & $700-800 \mathrm{kgDM} / \mathrm{ha}$ & [9] \\
\hline$r_{02}{ }^{1}$ & Forage production without precipitations & $5-10 \mathrm{kgDM} / \mathrm{ha}$ & [9] \\
\hline$r_{02}{ }^{2}$ & Water production without precipitations & $100-200 \mathrm{~mm} / \mathrm{yr}$ & [9] \\
\hline$p$ & Precipitations & $500-600 \mathrm{~mm} / \mathrm{yr}$ & {$[9]$} \\
\hline$r_{1}{ }^{1}$ & Intrinsic disappearance of forage resources & $90-120 \mathrm{kgDM} / \mathrm{ha}$ & [9] \\
\hline$r_{1}^{2}$ & Intrinsic disappearance of water resources & $150-250 \mathrm{~mm} / \mathrm{yr}$ & {$[9]$} \\
\hline$e_{1}$ & Forage biomass conversion rate & 0.015 per day & [10] \\
\hline$e_{2}$ & Water biomass conversion rate & 0.0154 per day & [10] \\
\hline$a_{1}$ & Herd's satiety rate from forage & $0.03 /$ ha & {$[10]$} \\
\hline$a_{2}$ & Herd's satiety rate from water & $0.02 / \mathrm{ha}$ & {$[10]$} \\
\hline$K_{1}$ & Maximal capacity of forage production & $7000-9000 \mathrm{kgDM} / \mathrm{ha}$ & {$[10]$} \\
\hline$K_{2}$ & Maximal capacity of water production & $900 \mathrm{~mm} / \mathrm{yr}$ & {$[10]$} \\
\hline$q_{1}$ & Forage utilization rate & 0.4 per day & [9] \\
\hline$q_{2}$ & Water utilization rate & 0.6 per day & [9] \\
\hline$m$ & Herd's removal rate & 1 per day & {$[10]$} \\
\hline
\end{tabular}

animals in the herd will coexist with the forage resources, exhibiting oscillatory balance behavior.

This can be explained by the resilience of vegetation, which means the ability of the ecosystem to withstand unusual stress and recover spontaneously once they have disappeared. Thus, an investigation in [18] showed that cereal production in the Sahel went from a deficit of one million tons in 1987 to surplus 1 million tons in 1988.

\subsection{Results of System (2)}

Lemma 9. The nonnegative orthant $I R_{+}^{2}$ is positively invariant by the trajectories of System (2), and the set $D_{2}=\{(R, W, H) \in$ $\left.I R_{+}^{3} / R \leq K_{1}, W \leq K_{2}\right\}$ is a compact forward and absorbing set for System (2).

Remark 10. Any trajectory with initial condition in the nonnegative orthant $I R_{+}^{3}$ is trapped and will stay inside. The nonnegative orthant $I R_{+}^{3}$ is then positively invariant and System (2) is mathematically well posed. We can then say that System (2) is well posed, since forage resources $R(t)$, water resources $W(t)$, and the tropical livestock unit of the herd $H(t)$ are always nonnegative quantities.

Theorem 11. Equilibria of System (2)

The equilibria $E_{10}=(0,0,0), E_{11}=\left(K_{1}, 0,0\right), E_{12}=$ $\left(0, K_{2}, 0\right)$, and $E_{13}=\left(K_{1}, K_{2}, 0\right)$ of System (2) exist without any condition, and

$$
\begin{aligned}
E_{2}= & \left(R^{*}, W^{*}, H^{*}\right) \\
= & \left(R^{*}, \frac{m a_{1} a_{2}+\left(m a_{2}-e_{1} q_{1} a_{2}\right) R^{*}}{\left(e_{2} q_{2} a_{1}-m a_{1}\right)+\left(e_{1} q_{1}+e_{2} q_{2}-m\right) R^{*}},\right. \\
& \left.\frac{r_{1}}{q_{1}}\left(1-\frac{R^{*}}{K_{1}}\right)\right)
\end{aligned}
$$

is an ecologically acceptable equilibrium if $R^{*}$ is a nonnegative value which satisfies equation

$$
c_{0}\left(R^{*}\right)^{4}+c_{1}\left(R^{*}\right)^{3}+c_{2}\left(R^{*}\right)^{2}+c_{3} R^{*}+c_{4}=0
$$

with $R^{*}>K_{1}, W^{*}>K_{2}$, and $e_{1} q_{1}<m<e_{2} q_{2}$, and the coefficients $c_{i}$ are given in Appendix $A$. 


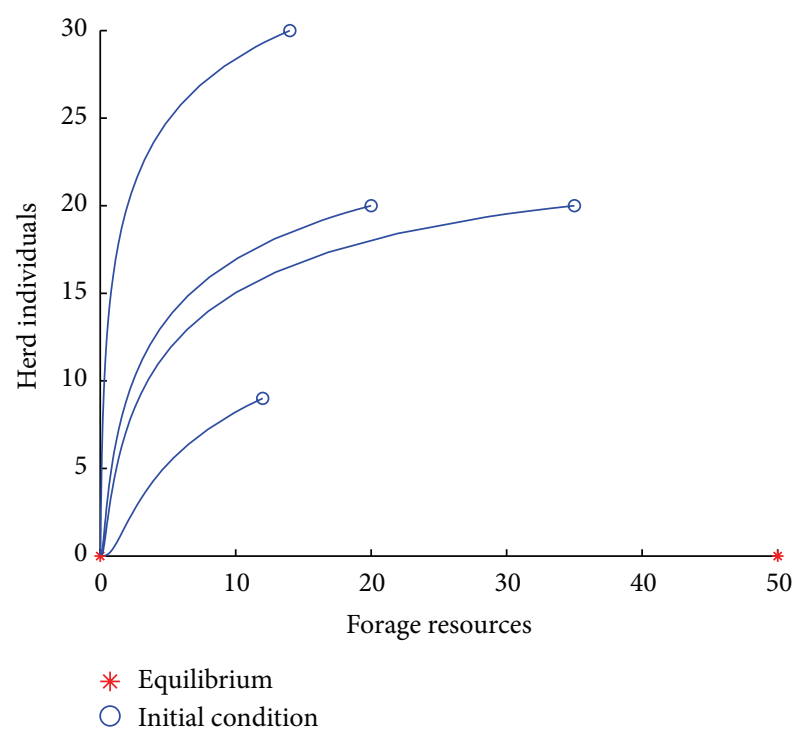

Figure 1: Phase portrait of the herd's animals and forage resources when $\mathrm{r}<0$. This illustrates the global stability of equilibrium $E_{0}=$ $(0,0)$ for System (1). This is a new situation, which happens during migration of pastoralists with their herds, calling transhumance; the pastoralists leave the area because of scarcity of forage resources. The parameters in this case are given in Table 1.

Proposition 12 (descartes criterion). The number of positive real roots of the polynomial equation is less than or equal to the number of changes in coefficient of ordered polynomial coefficients, and these two numbers have the same parity.

Proposition 13 (descartes rule of signs-I). The number of positive roots of the polynomial equation with real coefficients does not exceed the number of sign changes in its coefficients. A zero coefficient is not counted as a sign change.

Proposition 14 (descartes rule of signs-II). The number of positive roots of the polynomial equation with real coefficients does not exceed the number of sign changes in its coefficients and differs from it by a multiple of two. A zero coefficient is not counted as a sign change.

Using Descartes criterion and Descartes' rule of signs, the number of positive real roots of the polynomial equation given by (3) depends on the number of sign changes in its coefficients $\left(c_{0}, c_{1}, c_{2}, c_{3}, c_{4}\right)$.

Theorem 15. Stability of equilibria

(1) The equilibrium $E_{10}=(0,0,0)$ is a locally asymptotically stable node if $r_{1}<0$ and $r_{2}<0 . E_{10}$ is a saddlenode if $r_{1}<0$ and $r_{2}>0$ or $r_{1}>0$ and $r_{2}<0$.

(2) The equilibrium $E_{11}=\left(K_{1}, 0,0\right)$ is a locally asymptotically stable node if $r_{1}>0, r_{2}<0$, and $e_{1}\left(q_{1} K_{1} /\left(a_{1}+\right.\right.$ $\left.\left.K_{1}\right)\right)<m$.

(3) The equilibrium $E_{12}=\left(0, K_{2}, 0\right)$ is a locally asymptotically stable node if $r_{1}<0, r_{2}>0$, and $e_{2}\left(q_{2} K_{2} /\left(a_{2}+\right.\right.$ $\left.\left.K_{2}\right)\right)<m$.

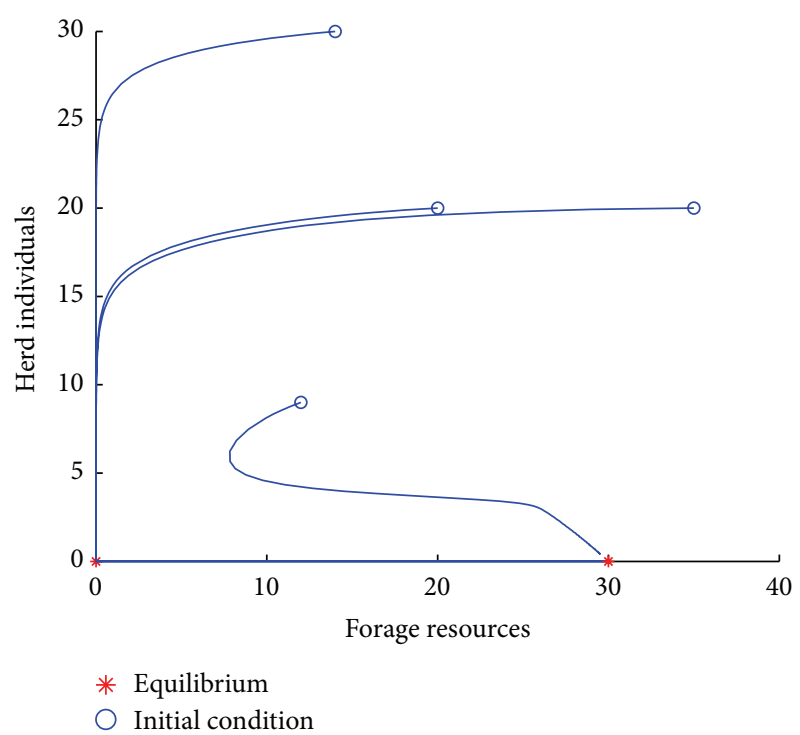

FIgURE 2: Phase portrait of System (1). Illustration of the local asymptotic stability of equilibrium $E_{0}=(0,0)$ and equilibrium $E_{1}=(K, 0)$. These situations happen during transhumance; the pastoralists leave the area because of scarcity of forage resources or some local conditions. The rest of parameters in this case are given in Table 1, with $r_{01}=200 \mathrm{kgDM} / \mathrm{ha}, r_{02}=55 \mathrm{kgDM} / \mathrm{ha}$, $r_{1}=80 \mathrm{kgDM} / \mathrm{ha}$, and $K=30 \mathrm{kgDM} /$ ha such that $r>0$.

(4) The equilibrium $E_{13}=\left(K_{1}, K_{2}, 0\right)$ is a locally asymptotically stable node if $r_{1}>0, r_{2}>0$, and $e_{1}\left(q_{1} K_{1} /\left(a_{1}+\right.\right.$ $\left.\left.K_{1}\right)\right)+e_{2}\left(q_{2} K_{2} /\left(a_{2}+K_{2}\right)\right)<m . E_{13}$ is a saddle-node if one or two of the three conditions are not satisfied and an unstable node if the three conditions are not satisfied.

(5) The coexisting equilibrium $E_{2}=\left(R^{*}, W^{*}, H^{*}\right)$ of System (2), given as previously by

$$
\begin{aligned}
E_{2}= & \left(R^{*}, W^{*}, H^{*}\right) \\
= & \left(R^{*}, \frac{m a_{1} a_{2}+\left(m a_{2}-e_{1} q_{1} a_{2}\right) R^{*}}{\left(e_{2} q_{2} a_{1}-m a_{1}\right)+\left(e_{1} q_{1}+e_{2} q_{2}-m\right) R^{*}},\right. \\
& \left.\frac{r_{1}}{q_{1}}\left(1-\frac{R^{*}}{K_{1}}\right)\right)
\end{aligned}
$$

when it exists, can be locally asymptotically stable if the RouthHurwitz conditions

$$
\begin{gathered}
H_{1}=v_{1}>0, \\
H_{2}=v_{1} v_{2}-v_{3}>0, \\
H_{3}=v_{3}>0
\end{gathered}
$$

are satisfied, where $v_{1}, v_{2}$, and $v_{3}$ are given as in the proof in Appendix B. Moreover, the system exhibits periodic oscillations with alternative peaks of forage, water, and the herd trajectories.

Remark 16. It is difficult for cattle to adequately live in Sahelian region when forage resources or water resources 

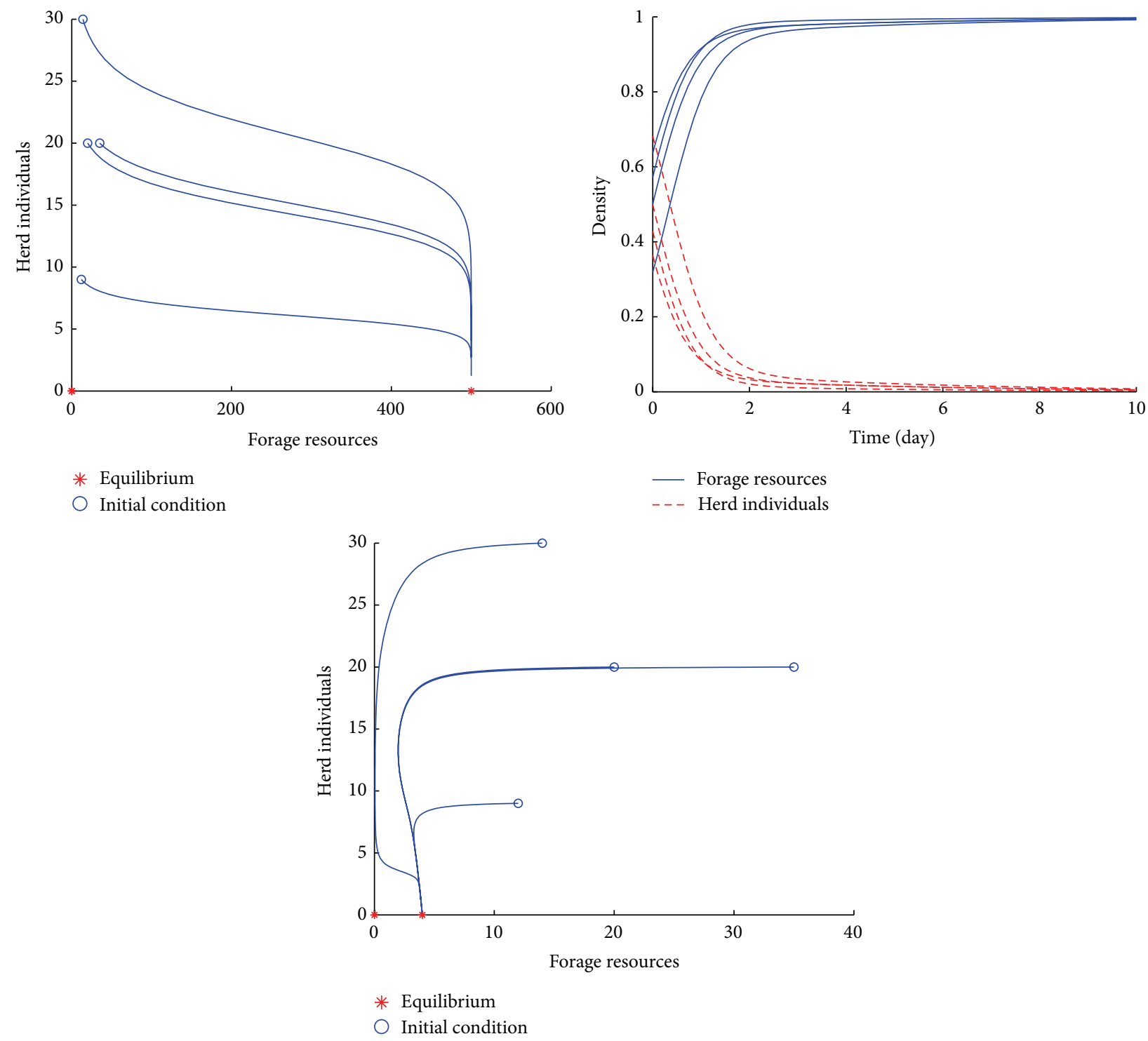

FIGURE 3: Chronological evolution and phase portrait of the herd individuals and forage resources of System (1) when $r_{01}=200 \mathrm{kgDM} / \mathrm{ha}$, $r_{02}=55 \mathrm{kgDM} / \mathrm{ha}, r_{1}=80 \mathrm{kgDM} / \mathrm{ha}, K=30-600 \mathrm{kgDM} / \mathrm{ha}, e=0.05 /$ day, $a=0.013 / \mathrm{ha}, q=0.4 /$ day, and $\gamma=0.07 /$ day. Global stability of equilibrium $E_{1}=(K, 0)$ for System (1). This illustrates the case when pastoralists decide to migrate for reasons different from unavailability of forage resources.

have dried up completely. When at least one of two completely lacks resources, pastoralists can be forced to migrate with livestock in order to avoid disaster. In addition, feed resources and water resources are often somewhat related since the fresh leaves have water content of about $80 \%$. Transhumance can therefore take place when one of the two resources has failed to herd and in this case, pastoralists migrate while the second resource is available in the area. The stability of $E_{10}, E_{11}, E_{12}$, and $E_{13}$ characterizes these situations. In usual predator-prey models, it is virtually impossible to have stability for $E_{10}, E_{11}$, and $E_{12}$, becausestability of $E_{10}$, for example,means thatthe entire population will disappear, which is not the main objective when coupling preys and predators. However, this is easily explained in pastoralism as it corresponds to transhumance.

\section{Numerical Simulations and Interpretations}

The parameters values come from $[9,10]$ and references therein, and we use the same method as in [9] to compute some parameters values. Let us recall these formulas, in order to have the livestock capacity in natural grassland.

(1) Assuming that the production volume of fresh grasses is $8000 \mathrm{~kg} / \mathrm{ha}$, the estimated water contained in fresh grasses is around $80 \%$ (this means $20 \%$ of dry matter). 


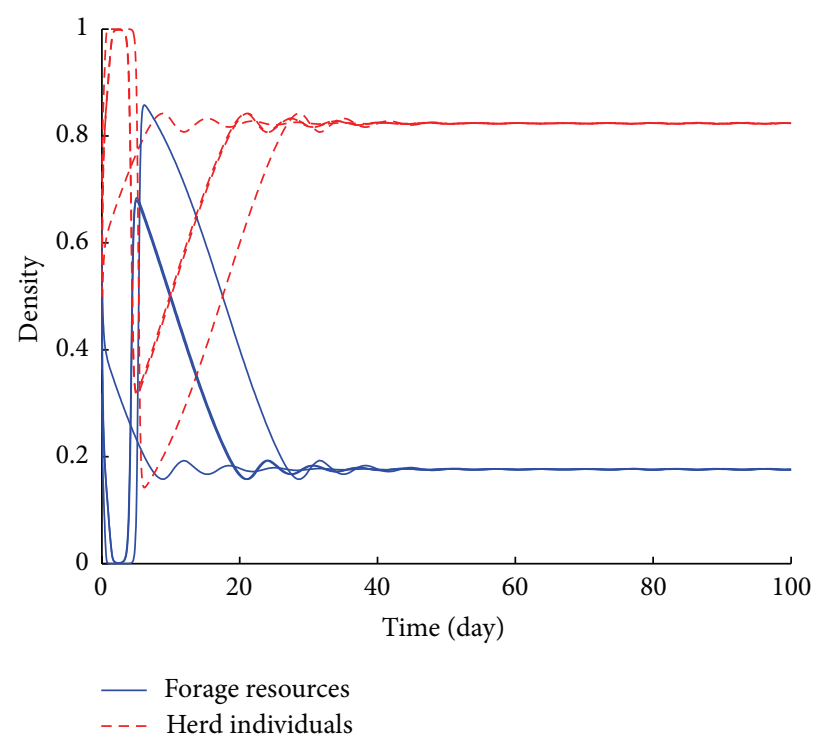

FIGURE 4: Chronological evolution of the herd's animals and forage resources of System (1) when $r=500 \mathrm{kgDM} / \mathrm{ha}, e=0.05 / \mathrm{day}, a=$ $0.013 / \mathrm{ha}, K=10-40 \mathrm{kgDM} / \mathrm{ha}, q=0.4 /$ day, and $\gamma=0.07 /$ day. Stability of the coexisting equilibrium $E_{2}=\left(R^{*}, H^{*}\right)$.
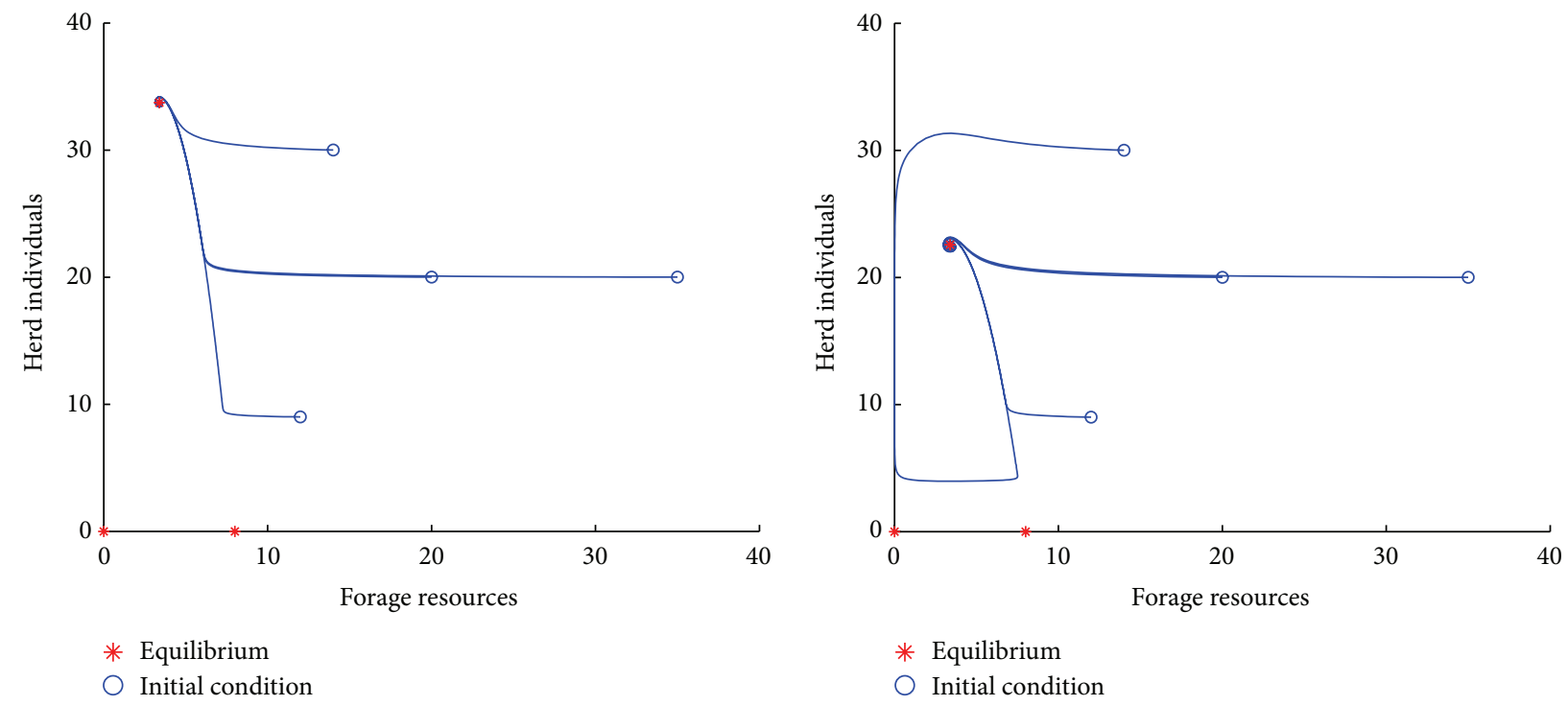

Figure 5: Phase portrait of the herd's animals and forage resources of System (1) when $r=500 \mathrm{kgDM} / \mathrm{ha}, e=0.05 / \mathrm{day}, a=0.013 / \mathrm{ha}$, $K=8-30 \mathrm{kgDM} / \mathrm{ha}, q=0.4 /$ day, and $\gamma=0.07 /$ day. Illustration of the stability of the unique coexisting equilibrium $E_{2}=\left(R^{*}, H^{*}\right)$ for four initial conditions.

(2) The dry matter (DM) obtained for the livestock is $5.2 \mathrm{~kg} /$ day for cattle and $1 \mathrm{~kg} /$ day for goats and sheep.

The production volume of the forage resources with $40 \%$ as utilization rate can then be computed:

$8000 \mathrm{~kg} / \mathrm{ha} \times 0.2 \times 0.4=640 \mathrm{kgDM} / \mathrm{ha}$.

The number of animals which is possible in pasture is then given by

$640 \mathrm{kgDM} / \mathrm{ha}:(5.2 \mathrm{kgDM} \times 365$ days $)=0.34 \mathrm{head} / \mathrm{ha}$ for cattle,
$640 \mathrm{kgDM} / \mathrm{ha}:(1.0 \mathrm{kgDM} \times 365$ days $)=1.75 \mathrm{head} / \mathrm{ha}$ for goats and sheep.

We also have in Tables 1 and 2 the parameters values obtained in $[9,10]$, which correspond to the situation where the intrinsic production $r=r_{01} p+r_{02}-r_{1}$ is negative. This means that, at this moment, the removal quantity of forage resources, which is due to competition or which is used to feed the livestock, is greater than the intrinsic production. This situation can force pastoralists to leave the area and migrate elsewhere in order to feed their herds. 


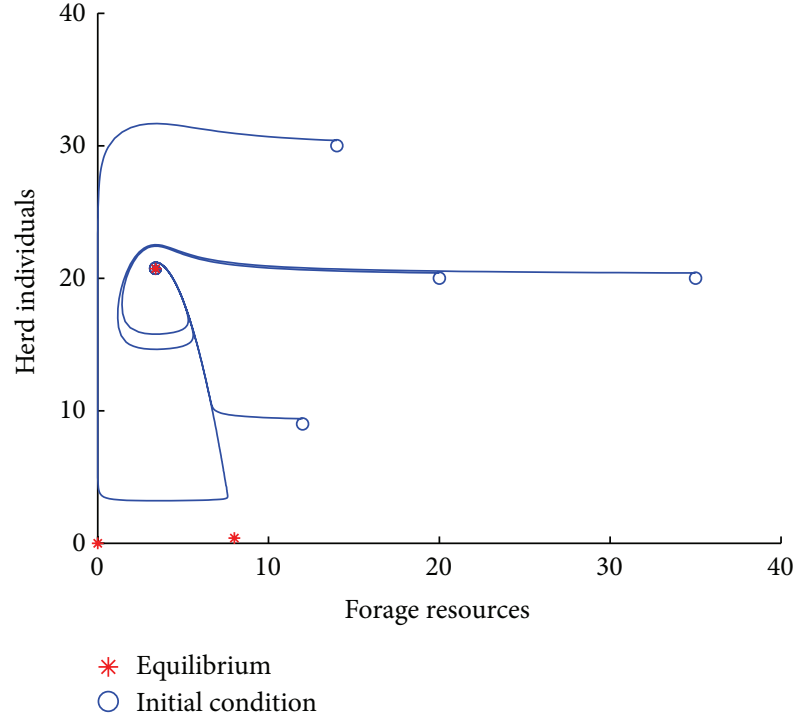

Figure 6: Phase portrait of the herd's animals and forage resources of System (1) when $r=500 \mathrm{kgDM} / \mathrm{ha}, e=0.05 /$ day, $a=0.013 / \mathrm{ha}$, $K=8-30 \mathrm{kgDM} / \mathrm{ha}, q=0.4 /$ day, and $\gamma=0.07 /$ day. Illustration of the stability of the unique coexisting equilibrium $E_{2}=\left(R^{*}, H^{*}\right)$ for four initial conditions.

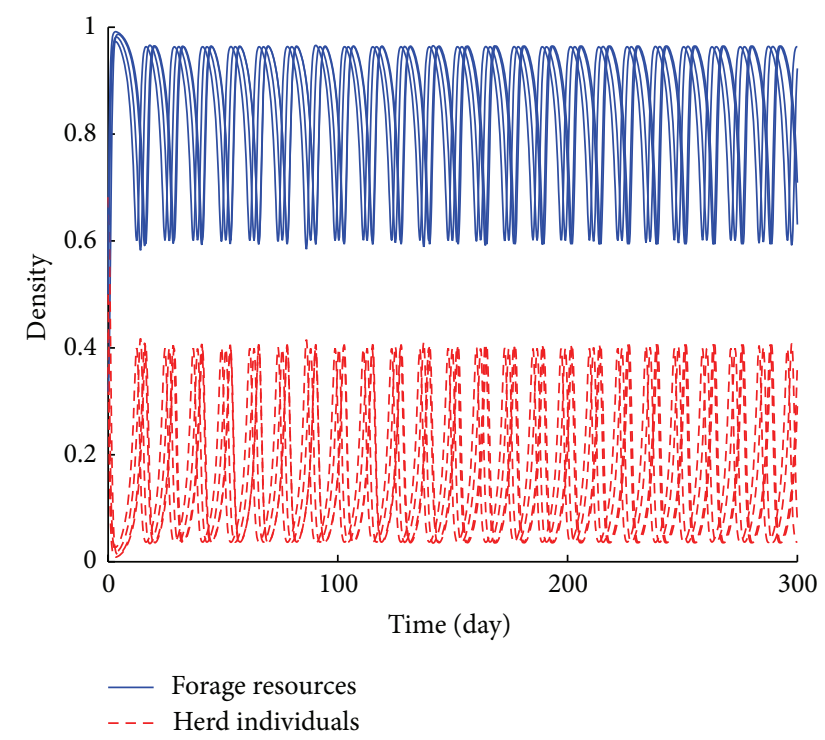

Figure 7: Chronological evolution of the herd's animals and forage resources of System (1) when $r=650 \mathrm{kgDM} / \mathrm{ha}, e=0.05 /$ day, $a=0.013 / \mathrm{ha}, K=800 \mathrm{kgDM} / \mathrm{ha}, q=0.4 /$ day, and $\gamma=1.0 /$ day. This illustrates the global stability of the unique coexisting equilibrium $E_{2}=\left(R^{*}, H^{*}\right)$. This means that the herd's animals and forage resources have periodic curves since there is a stable limit cycle. The two populations can exist together.

Figure 1 illustrates global stability of equilibrium $(0,0)$. Figure 2 illustrates coexistence and local stability of equilibria $(0,0)$ and $(K, 0)$. Figure 3 illustrates the global asymptotic stability of equilibrium $(K, 0)$. Figures 4 and 5 illustrate the global asymptotic stability of equilibrium $E_{2}=\left(R^{*}, H^{*}\right)$. Figures 6,7 , and 8 illustrate existence of periodic solutions and then Hopf bifurcation with a stable limit cycle.

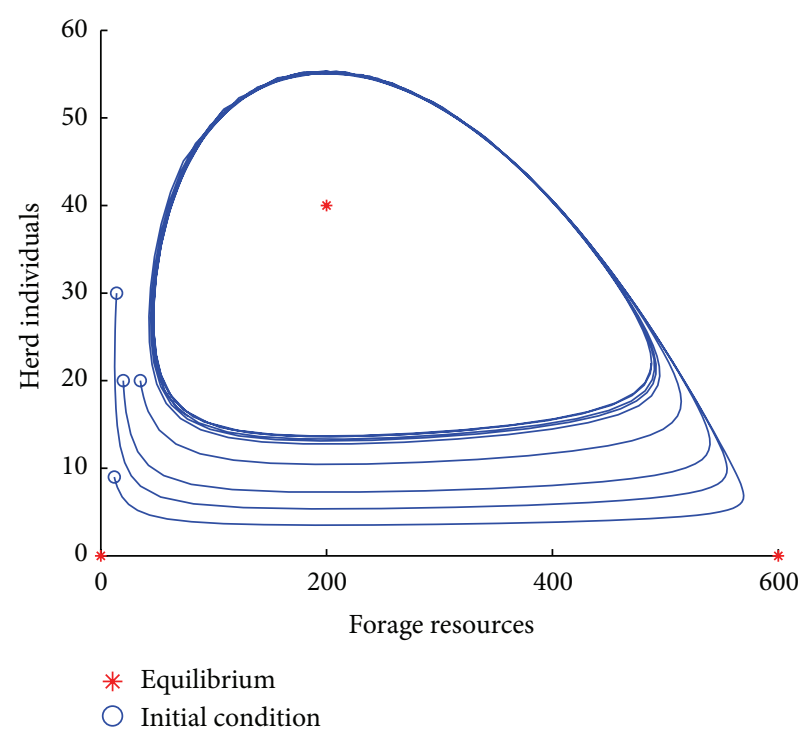

FIGURE 8: Phase portrait for illustration of a stable limit cycle around coexisting equilibrium of System (1) for $E_{2}=\left(R^{*}, H^{*}\right)$ for $r=$ $700 \mathrm{kgDM} / \mathrm{ha}, e=0.05 /$ day, $a=0.013 / \mathrm{ha}, K=960 \mathrm{kgDM} / \mathrm{ha}$, $q=0.4 /$ day, and $\gamma=1.0 /$ day. This means that there is a supercritical Hopf bifurcation.

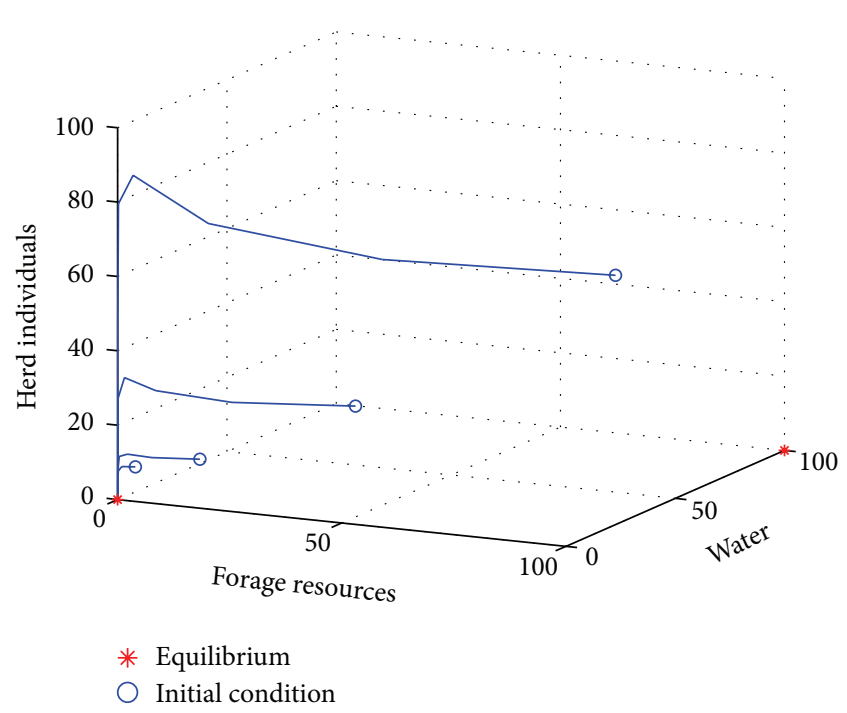

FIGURE 9: Phase portrait corresponding to the disappearing of forage resources and water resources and removal of the pastoralists with their herds for System (2). We can observe here the global asymptotic stability of $E_{10}=(0,0,0)$ when $r_{1}=-0.4<0$ and $r_{2}=-60<0$. The rest of parameters are in Tables 1 and 2 .

Figure 9 illustrates the global asymptotic stability of equilibrium $(0,0,0)$. Figure 10 illustrates the local stability of equilibria $E_{10}, E_{11}$, and $E_{12}$. Figure 11 illustrates existence of periodic solutions with alternative peaks of trajectories. Figure 12 illustrates the global stability of equilibrium $E_{13}=$ $\left(K_{1}, K_{2}, 0\right)$. 

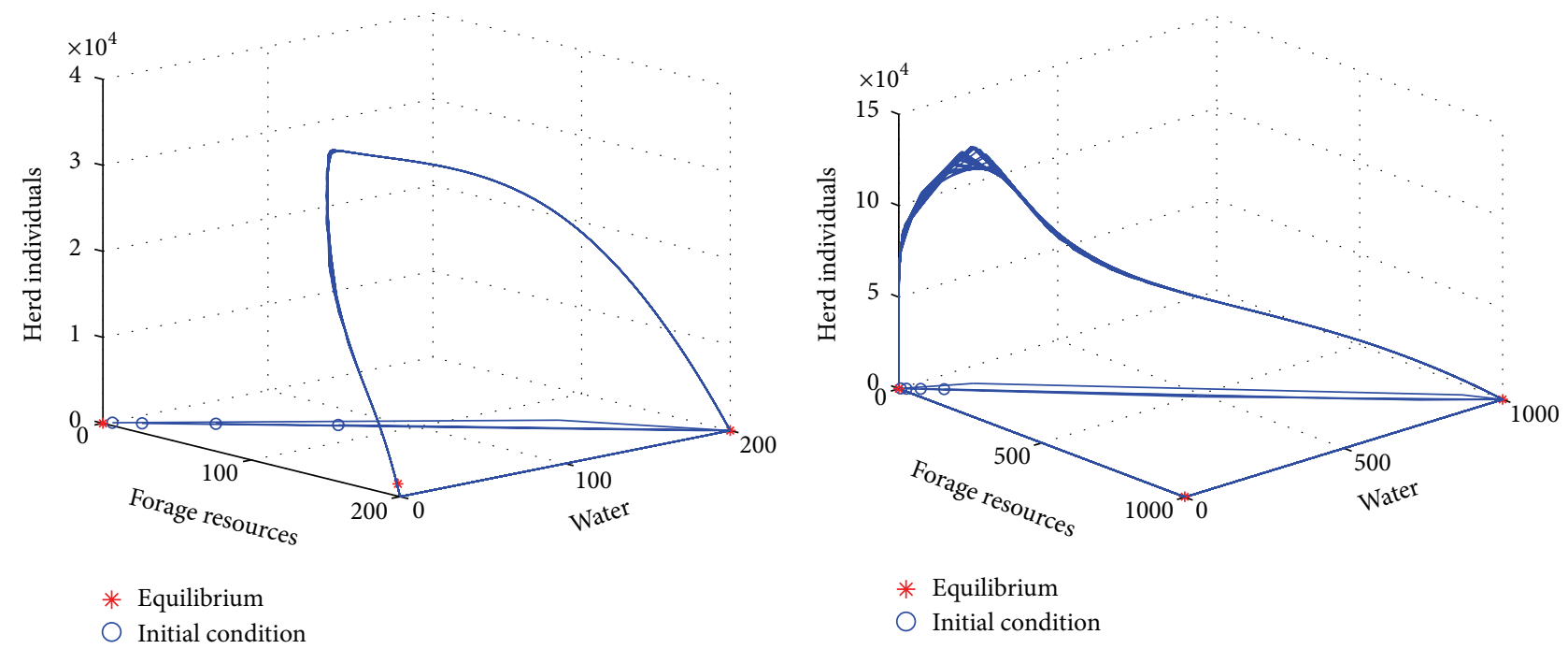

FIGURE 10: Phase portrait of System (2) showing the coexistence of $E_{10}, E_{11}, E_{12}$. Equilibria $E_{11}$ and $E_{12}$ correspond to the removal of the pastoralists with their herd and persistence of forage or water resources. We can observe here the local asymptotic stability of $E_{11}=\left(K_{1}, 0,0\right)$, $E_{12}=\left(0, K_{2}, 0\right)$, and $E_{10}=(0,0,0)$ when $r_{1}=400 \mathrm{kgDM} / \mathrm{ha}$ and $p=3000 \mathrm{~mm}$. The rest of parameters are in Tables 1 and 2.

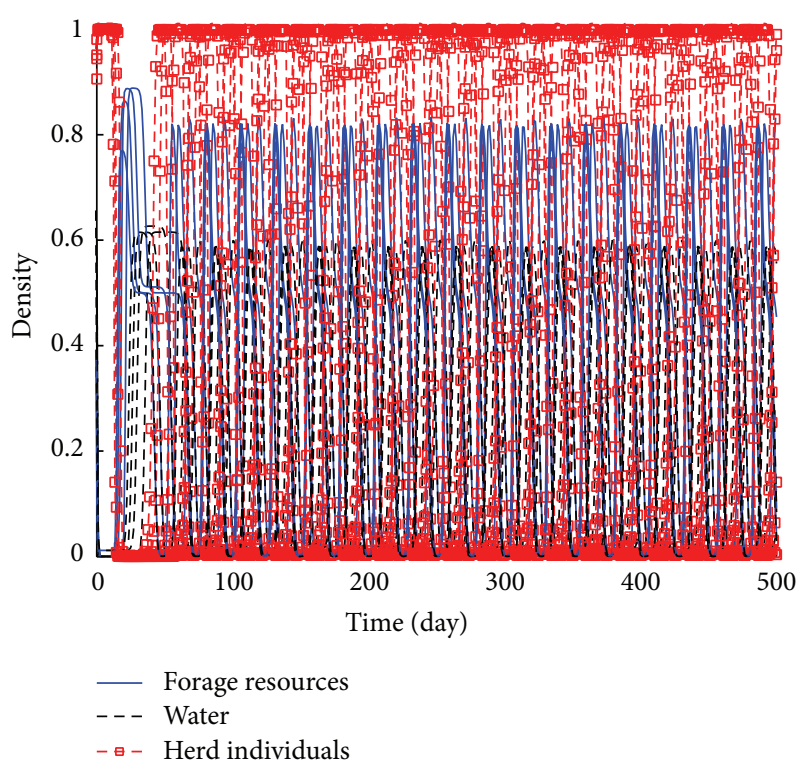

FIGURE 11: Illustration of periodicity of the trajectories at equilibrium $E_{2}=\left(R^{*}, W^{*}, H^{*}\right)$ for System (2). Alternative peaks are observed between the trajectories of the flock, feed resources, and water resources when $r_{1}=800 \mathrm{kgDM} / \mathrm{ha}, r_{2}=700 \mathrm{kgDM} / \mathrm{ha}$, $p=600 \mathrm{~mm}, K_{1}=1000 \mathrm{kgDM} / \mathrm{ha}$, and $K_{2}=900 \mathrm{kgDM} / \mathrm{ha}$. The rest of parameters are in Tables 1 and 2.

\section{Conclusion}

A mathematical model for pastoralism has been considered in order to explain and predict some situations in Sahelian region. This is one of the first deterministic models of pastoralism analyzed with interpretations. The results obtained in this paper have been simulated with the data in $[9,10]$ and confirm many observations throughout pastoralism's

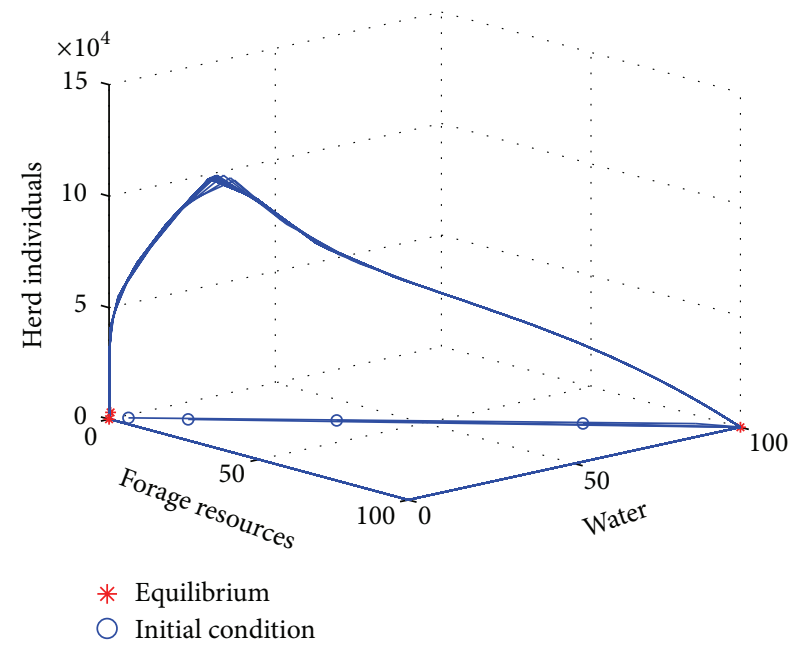

Figure 12: (a) Chronological evolution of herd's animals, forage, and water resources of System (2). We observe the global stability of equilibrium $E_{13}=\left(K_{1}, K_{2}, 0\right)$ when $r_{1}=200 \mathrm{kgDM} / \mathrm{ha}, r_{2}=$ $300 \mathrm{kgDM} / \mathrm{ha}, p=600 \mathrm{~mm}, K_{1}=800 \mathrm{kgDM} / \mathrm{ha}$, and $K_{2}=$ $900 \mathrm{kgDM} / \mathrm{ha}$. (b) Phase portrait of System (2) showing the local stability of equilibria $E_{11}$ and $E_{12}$. The rest of parameters are in Tables 1 and 2.

literature concerning interactions of forage resources and herds. At the end of this first part, we can say that since forage resources can be also considered sometimes as water resources, it will be better for us to add in the previous equations of System (1) another equation in order to take into account the water resources.

The statistics show the importance of livestock to the national economy in tropical arid countries. Two opposing trends develop: the continued contribution of livestock in 
national economy and the growing risk of deterioration of pastoral resource savings.

Sustainable pastoral resource management, equitable and secured access to pastoral resources, and peace and security which are always the aims of framework policy are also the guidelines of our contribution to pastoralism by mathematical models. Thus, it is necessary that these issues be addressed through a comprehensive pastoral policy, which confers full political, social, economic, and environmental benefits to the pastoral communities. The deterministic models proposed and analyzed in this paper are firstly to participate to these efforts. Although considerable efforts with some positive results are being made throughout Africa, a great deal more still needs to be done. This calls for both commitments from individual countries and cooperation at the regional and continental levels. We think that mathematical models can considerably contribute to increasing comprehension of pastoralism and therefore increase the quality of life of pastoralists. The models considered in this paper exhibit periodic oscillations when some conditions are satisfied. The comprehension of conditions to have periodic oscillations and then coexistence of herds, forage, and water resources can help pastoralists to better understand their environment. With this coexistence, there are alternative peaks of livestock tropical unit, forage resources, and water resources. This means that when these conditions are satisfied, pastoralists can live in some areas without transhumance, with disponibility of forage and water resources.

\section{Appendices}

\section{A. Expression of coefficients in Theorem 11}

The points $E_{10}, E_{11}, E_{12}$, and $E_{13}$ are obviously equilibria of System (2) without any condition. The coexisting equilibrium is given by the system

$$
\begin{gathered}
H^{*}=\frac{r_{1}}{q_{1}}\left(1-\frac{R^{*}}{K_{1}}\right)\left(a_{1}+R^{*}\right)=\frac{r_{2}}{q_{2}}\left(1-\frac{W^{*}}{K_{2}}\right)\left(a_{2}+W^{*}\right), \\
\frac{r_{1}}{q_{1}}\left(1-\frac{R^{*}}{K_{1}}\right)\left(a_{1}+R^{*}\right)=\frac{r_{2}}{q_{2}}\left(1-\frac{W^{*}}{K_{2}}\right)\left(a_{2}+W^{*}\right), \\
e_{1} q_{1} \frac{R^{*}}{a_{1}+R^{*}}+e_{2} q_{2} \frac{W^{*}}{a_{2}+W^{*}}=m .
\end{gathered}
$$

The third equation implies

$$
W^{*}=\frac{m a_{1} a_{2}+\left(m a_{2}-e_{1} q_{1} a_{2}\right) R^{*}}{\left(e_{2} q_{2} a_{1}-m a_{1}\right)+\left(e_{1} q_{1}+e_{2} q_{2}-m\right) R^{*}} .
$$

The expressions of $H^{*}$ and $W^{*}$ are positives if $R^{*}>K_{1}, W^{*}>$ $K_{2}$, and $e_{1} q_{1}<m<e_{2} q_{2}$. In order to give the expression of $R^{*}$, let us consider the second equation of the system

$$
\begin{aligned}
& a_{1} \frac{r_{1}}{q_{1}}+\frac{r_{1}}{q_{1}} R^{*}-\frac{a_{1} r_{1}}{K_{1} q_{1}} R^{*}-\frac{r_{1}}{K_{1} q_{1}}\left(R^{*}\right)^{2} \\
& =a_{2} \frac{r_{2}}{q_{2}}+\frac{r_{2}}{q_{2}} W^{*}-\frac{a_{2} r_{2}}{K_{2} q_{2}} W^{*}-\frac{r_{2}}{K_{2} q_{2}}\left(W^{*}\right)^{2} .
\end{aligned}
$$

Then, setting $\gamma_{1}=m a_{2}-e_{1} q_{1} a_{2}, \gamma_{2}=e_{2} q_{2} a_{1}-m a_{1}$, and $\gamma_{3}=e_{1} q_{1}+e_{2} q_{2}-m$, the previous equation finally becomes

$$
\begin{aligned}
a_{1} \frac{r_{1}}{q_{1}} K_{2} q_{2} \gamma_{2}^{2}+2 a_{1} \frac{r_{1}}{q_{1}} K_{2} q_{2} \gamma_{2} \gamma_{3} R^{*} \\
+a_{1} \frac{r_{1}}{q_{1}} K_{2} q_{2} \gamma_{3}^{2}\left(R^{*}\right)^{2}+\frac{r_{1}}{q_{1}} K_{2} q_{2} \gamma_{2}^{2} \\
\quad-a_{1} r_{1} \frac{K_{2} q_{2}}{K_{1} q_{1}} \gamma_{2}^{2} R^{*}-2 a_{1} r_{1} \frac{K_{2} q_{2}}{K_{1} q_{1}} \gamma_{2} \gamma_{3}\left(R^{*}\right)^{2} \\
\quad-a_{1} r_{1} \frac{K_{2} q_{2}}{K_{1} q_{1}} \gamma_{3}^{2}\left(R^{*}\right)^{3}-r_{1} \frac{K_{2} q_{2}}{K_{1} q_{1}} \gamma_{2}^{2}\left(R^{*}\right)^{2} \\
+2 \frac{r_{1}}{q_{1}} K_{2} q_{2} \gamma_{2} \gamma_{3} R^{*}+\frac{r_{1}}{q_{1}} K_{2} q_{2} \gamma_{3}^{2}\left(R^{*}\right)^{3} \\
\quad-2 r_{1} \frac{K_{2} q_{2}}{K_{1} q_{1}} \gamma_{2} \gamma_{3}\left(R^{*}\right)^{3}-r_{1} \frac{K_{2} q_{2}}{K_{1} q_{1}} \gamma_{3}^{2}\left(R^{*}\right)^{4} \\
=a_{2} K_{2} r_{2} \gamma_{2}^{2}+2 a_{2} K_{2} r_{2} \gamma_{2} \gamma_{3} R^{*}+a_{2} K_{2} r_{2} \gamma_{3}^{2}\left(R^{*}\right)^{2} \\
+m_{1} a_{2} \gamma_{2}\left(K_{2} r_{2}-a_{2} r_{2}\right) \\
+\left(K_{2} r_{2}-a_{2} r_{2}\right)\left(m a_{1} a_{2} \gamma_{3}+\gamma_{1} \gamma_{2}\right) R^{*} \\
\quad \times \gamma_{1} \gamma_{3}\left(K_{2} r_{2}-a_{2} r_{2}\right)\left(R^{*}\right)^{2}-r_{2}\left(m a_{1} a_{2}\right)^{2} \\
-2 r_{2} m a_{1} a_{2} \gamma_{1} R^{*}-r_{2} \gamma_{1}^{2}\left(R^{*}\right)^{2} .
\end{aligned}
$$

This polynomial can be written in the following form:

$$
c_{0}\left(R^{*}\right)^{4}+c_{1}\left(R^{*}\right)^{3}+c_{2}\left(R^{*}\right)^{2}+c_{3} R^{*}+c_{4}=0,
$$

where

$$
\begin{aligned}
c_{0}= & r_{1} \frac{K_{2} q_{2}}{K_{1} q_{1}} \gamma_{3}^{2}>0, \\
c_{1}= & 2 r_{1} \frac{K_{2} q_{2}}{K_{1} q_{1}} \gamma_{2} \gamma_{3}+\frac{r_{1}}{q_{1}} K_{2} q_{2} \gamma_{3}^{2}\left(\frac{a_{1}}{K_{1}}-1\right), \\
c_{2}= & -a_{1} \frac{r_{1}}{q_{1}} K_{2} q_{2} \gamma_{3}^{2}+2 a_{1} r_{1} \frac{K_{2} q_{2}}{K_{1} q_{1}} \gamma_{2} \gamma_{3}+r_{1} \frac{K_{2} q_{2}}{K_{1} q_{1}} \gamma_{2}^{2} \\
& +a_{2} K_{2} r_{2} \gamma_{3}^{2}+\gamma_{1} \gamma_{2}\left(K_{2} r_{2}-a_{2} r_{2}\right)-r_{2} \gamma_{1}^{2}, \\
c_{3}= & -2 a_{1} \frac{r_{1}}{q_{1}} K_{2} q_{2} \gamma_{2} \gamma_{3}-2 \frac{r_{1}}{q_{1}} K_{2} q_{2} \gamma_{2} \gamma_{3} \\
& +a_{1} r_{1} \frac{K_{2} q_{2}}{K_{1} q_{1}} \gamma_{2}^{2}+2 a_{2} K_{2} r_{2} \gamma_{2} \gamma_{3} \\
& +\left(K_{2} r_{2}-a_{2} r_{2}\right)\left(m a_{1} a_{2} \gamma_{3}+\gamma_{1} \gamma_{2}\right)-r_{2}\left(m a_{1} a_{2}\right)^{2} \\
& -2 r_{2} m a_{1} a_{2} \gamma_{1}, \\
c_{4}= & -a_{1} \frac{r_{1}}{q_{1}} K_{2} q_{2} \gamma_{2}^{2}-\frac{r_{1}}{q_{1}} K_{2} q_{2} \gamma_{2}^{2}+a_{2} K_{2} r_{2} \gamma_{2}^{2} \\
& +m a_{1} a_{2} \gamma_{2}\left(K_{2} r_{2}-a_{2} r_{2}\right) .
\end{aligned}
$$




\section{B. Proof of Theorem Theorem 15}

(1) At equilibrium $E_{10}$, the eigenvalues of the Jacobian matrix are $\lambda_{1}=r_{1}, \lambda_{2}=r_{2}$, and $\lambda_{3}=-m$. Then, $E_{10}$ is a locally asymptotically stable node if $r_{1}<0$ and $r_{2}<0$.

(2) At equilibrium $E_{11}$, the eigenvalues of the Jacobian matrix are $\lambda_{1}=-r_{1}, \lambda_{2}=r_{2}$, and $\lambda_{3}=-m+e_{1}\left(q_{1} K_{1} /\left(a_{1}+\right.\right.$ $\left.K_{1}\right)$ ). Then, $E_{11}$ is a locally asymptotically stable node if $r_{1}>0$, $r_{2}<0$, and $e_{1}\left(q_{1} K_{1} /\left(a_{1}+K_{1}\right)\right)<m$.

(3) At equilibrium $E_{12}$, the eigenvalues of the Jacobian matrix are $\lambda_{1}=-r_{1}, \lambda_{2}=r_{2}$, and $\lambda_{3}=-m+e_{2}\left(q_{2} K_{2} /\left(a_{2}+\right.\right.$
$\left.\left.K_{2}\right)\right)$. Then, $E_{12}$ is a locally asymptotically stable node if $r_{1}>0$, $r_{2}<0$, and $e_{2}\left(q_{2} K_{2} /\left(a_{2}+K_{2}\right)\right)<m$.

(4) At equilibrium $E_{13}$, the eigenvalues of the Jacobian matrix are $\lambda_{1}=-r_{1}, \lambda_{2}=-r_{2}$, and $\lambda_{3}=-m+e_{1}\left(q_{1} K_{1} /\left(a_{1}+\right.\right.$ $\left.\left.K_{1}\right)\right)+e_{2}\left(q_{2} K_{2} /\left(a_{2}+K_{2}\right)\right)$. Then, $E_{13}$ is a locally asymptotically stable node if $r_{1}>0, r_{2}>0$, and $e_{1}\left(q_{1} K_{1} /\left(a_{1}+K_{1}\right)\right)+$ $e_{2}\left(q_{2} K_{2} /\left(a_{2}+K_{2}\right)\right)<m$. The herd will disappear, and forage resources and water resources will go to the maximal storage capacity.

(5) At equilibrium $\left(R^{*}, W^{*}, H^{*}\right)$, using the relations in System (2) gives the Jacobian matrix

$$
J\left(R^{*}, W^{*}, H^{*}\right)=\left(\begin{array}{ccc}
-\frac{r_{1}}{q_{1}} R^{*}+\frac{q_{1} R^{*} H^{*}}{\left(a_{1}+R^{*}\right)^{2}} & 0 & -\frac{q_{1} R^{*}}{a_{1}+R^{*}} \\
0 & -\frac{r_{2}}{q_{2}} W^{*}+\frac{q_{2} W^{*} H^{*}}{\left(a_{2}+W^{*}\right)^{2}} & -\frac{q_{2} W^{*}}{a_{2}+W^{*}} \\
e_{1} \frac{q_{1} H^{*}}{a_{1}+R^{*}}-e_{1} \frac{q_{1} R^{*} H^{*}}{\left(a_{1}+R^{*}\right)^{2}} & e_{2} \frac{q_{2} H^{*}}{a_{2}+W^{*}}-e_{2} \frac{q_{2} W^{*} H^{*}}{\left(a_{2}+W^{*}\right)^{2}} & 0
\end{array}\right) .
$$

The characteristic polynomial is in the form

$$
p(\lambda)=\lambda^{3}+v_{1} \lambda^{2}+v_{2} \lambda+v_{3}=0,
$$

where

$$
\begin{aligned}
& v_{1}=\frac{r_{2}}{K_{2}} W^{*}-\frac{q_{2} W^{*} H^{*}}{\left(a_{2}+W^{*}\right)^{2}}+\frac{r_{1}}{K_{1}} R^{*}-\frac{q_{1} R^{*} H^{*}}{\left(a_{1}+R^{*}\right)^{2}}, \\
v_{2}= & \frac{r_{1}}{K_{1}} R^{*} \frac{r_{2}}{K_{2}} W^{*}-\frac{r_{2}}{K_{2}} W^{*} \frac{q_{1} R^{*} H^{*}}{\left(a_{1}+R^{*}\right)^{2}}-\frac{r_{1}}{K_{1}} R^{*} \frac{q_{2} W^{*} H^{*}}{\left(a_{2}+W^{*}\right)^{2}} \\
& -\frac{q_{2} W^{*}}{a_{2}+W^{*}} \frac{r_{1}}{K_{1}} R^{*} \frac{e_{2} q_{2} H^{*}}{a_{2}+W^{*}} \\
& +\frac{q_{2} W^{*}}{a_{2}+W^{*}} \frac{r_{1}}{K_{1}} R^{*} \frac{e_{2} q_{2} W^{*} H^{*}}{\left(a_{2}+W^{*}\right)^{2}} \\
& +\frac{q_{2} W^{*}}{a_{2}+W^{*}} \frac{q_{1} R^{*} H^{*}}{\left(a_{1}+R^{*}\right)^{2}} \frac{e_{2} q_{2} H^{*}}{a_{2}+W^{*}} \\
& -\frac{q_{2} W^{*}}{a_{2}+W^{*}} \frac{e_{2} q_{2} W^{*} H^{*}}{\left(a_{2}+W^{*}\right)^{2}} \frac{q_{1} R^{*} H^{*}}{\left(a_{1}+R^{*}\right)^{2}} \\
& +\frac{q_{1} R^{*}}{a_{1}+R^{*}} \frac{r_{2}}{K_{2}} W^{*} \frac{q_{1} H^{*}}{a_{1}+R^{*}} \\
& -\frac{q_{1} R^{*}}{a_{1}+R^{*}} \frac{r_{2}}{K_{2}} W^{*} \frac{e_{1} q_{1} R^{*} H^{*}}{\left(a_{1}+R^{*}\right)^{2}}
\end{aligned}
$$$$
\begin{aligned}
& -\frac{q_{1} R^{*}}{a_{1}+R^{*}} \frac{e_{1} q_{1} H^{*}}{a_{1}+R^{*}} \frac{q_{2} W^{*} H^{*}}{\left(a_{2}+W^{*}\right)^{2}} \\
& +\frac{q_{1} R^{*}}{a_{1}+R^{*}} \frac{e_{1} q_{1} R^{*} H^{*}}{\left(a_{1}+R^{*}\right)^{2}} \frac{q_{2} W^{*} H^{*}}{\left(a_{2}+W^{*}\right)^{2}},
\end{aligned}
$$$$
v_{3}=\frac{q_{2} W^{*}}{a_{2}+W^{*}} \frac{r_{1}}{K_{1}} R^{*} \frac{e_{2} q_{2} H^{*}}{a_{2}+W^{*}}-\frac{q_{2} W^{*}}{a_{2}+W^{*}} \frac{r_{1}}{K_{1}} R^{*} \frac{e_{2} q_{2} W^{*} H^{*}}{\left(a_{2}+W^{*}\right)^{2}}
$$$$
-\frac{q_{2} W^{*}}{a_{2}+W^{*}} \frac{q_{1} R^{*} H^{*}}{\left(a_{1}+R^{*}\right)^{2}} \frac{e_{2} q_{2} H^{*}}{a_{2}+W^{*}}
$$$$
+\frac{q_{2} W^{*}}{a_{2}+W^{*}} \frac{q_{1} R^{*} H^{*}}{\left(a_{1}+R^{*}\right)^{2}} \frac{e_{2} q_{2} W^{*} H^{*}}{\left(a_{2}+W^{*}\right)^{2}}
$$$$
+\frac{q_{1} R^{*}}{a_{1}+R^{*}} \frac{r_{2}}{K_{2}} W^{*} \frac{e_{1} q_{1} H^{*}}{a_{1}+R^{*}}-\frac{q_{1} R^{*}}{a_{1}+R^{*}} \frac{r_{2}}{K_{2}} W^{*} \frac{e_{1} q_{1} R^{*} H^{*}}{\left(a_{1}+R^{*}\right)^{2}}
$$$$
-\frac{q_{1} R^{*}}{a_{1}+R^{*}} \frac{e_{1} q_{1} H^{*}}{a_{1}+R^{*}} \frac{q_{2} W^{*} H^{*}}{\left(a_{2}+W^{*}\right)^{2}}
$$$$
+\frac{q_{1} R^{*}}{a_{1}+R^{*}} \frac{e_{1} q_{1} R^{*} H^{*}}{\left(a_{1}+R^{*}\right)^{2}} \frac{q_{2} W^{*} H^{*}}{\left(a_{2}+W^{*}\right)^{2}} .
$$

The Routh-Hurwitz conditions for stability of this equilibrium are

$$
\begin{gathered}
H_{1}=v_{1}>0, \\
H_{2}=v_{1} v_{2}-v_{3}>0, \\
H_{3}=v_{3}>0 .
\end{gathered}
$$


When these conditions are satisfied, a coexisting equilibrium when it exists is locally asymptotically stable and globally asymptotically stable if there is a unique coexisting equilibrium. This ends the proof.

\section{Conflict of Interests}

The authors declare that there is no conflict of interests regarding the publication of this paper.

\section{References}

[1] Humanitarian Policy Group, Pastoralism, Policies and Practice in the Horn and East Africa A Review of Current Trends, 2009, http://www.odihpn.org/.

[2] CTA Policy Brief, Protecting and promoting pastoralism in Africa, N6, 2012, http://www.cta.int/.

[3] J. G. Galaty and D. L. Johnson, The World of Pastoralism: Herding Systems in Perspective, The Guilford Press, London, UK, 1990.

[4] J. G. Galaty and B. Pierre, Herders, Warriors, and Traders: Pastoralism in Africa, Westview, Boulder, Colo, USA, 1991.

[5] Department of Rural Economy and Agriculture, Policy Framework for Pastoralism in Africa: Securing, Protecting and Improving the Lives, Livelihoods and Rights of Pastoralist Communities, 2010, African Union, http://www.au.int/.

[6] M. Carrière, Impact des systèmes d'élevage pastoraux sur l'environnement en Afrique et en Asie tropicale et sub-tropicale aride et sub-aride, Livestock and the Environment Finding a Balance, Scientific Environmental Monitoring Group, 1996.

[7] A. B. Smith, "Origins and spread of pastoralism in Africa," Nomadic Peoples, vol. 32, pp. 91-105, 1993.

[8] G. K. Boudet, "Connaissance et gestion de l'espace pastoral sahélien," in Terroirs Pastoraux et Agropastoraux en Zone Tropicale, J. Audru, G. Boudet, J. Cesar et al., Eds., vol. 24 of Gestion, Aménagement et Intensification Fourragère. Etudes et Synthèses, 1992.

[9] S. Karimata, Guide technique de l'élevage , Le développement pastoral efficace passe par la production d'herbe, Documentation technique de la JGRC, Générer l'abondance dans le Sahel par la lutte contre la désertification, Vol 7, overseasactivities@green.go.jp,2001.

[10] Système d'Information sur le Pastoralisme au Sahel: Atlas des Évolutions des Systèmes Pastoraux au Sahel 1970-2012, FAO et CIRAD, 2012.

[11] J. J. Tewa, V. Y. Djeumen, and S. Bowong, "Predator-Prey model with Holling response function of type II and SIS infectious disease," Applied Mathematical Modelling, vol. 37, no. 7, pp. 4825-4841, 2013.

[12] Y. Hsieh and C. Hsiao, "Predator-prey model with disease infection in both populations," Mathematical Medicine and Biology, vol. 25, no. 3, pp. 247-266, 2008.

[13] J. J. Tewa, S. Bowong, and S. C. Oukouomi Noutchie, "Mathematical analysis of a two-patch model of tuberculosis disease with staged progression," Applied Mathematical Modelling, vol. 36, no. 12, pp. 5792-5807, 2012.

[14] A. Atangana and N. Bildik, "Approximate solution of tuberculosis disease population dynamics model," Abstract and Applied Analysis, vol. 2013, Article ID 759801, 8 pages, 2013.

[15] A. Atangana and E. Alabaraoye, "Solving a system of fractional partial differential equations arising in the model of HIV infection of $\mathrm{CD}^{+}$cells and attractor one-dimensional KellerSegel equations," Advances in Difference Equations, vol. 2013, article 94, 2013.

[16] D. S. Boukal and V. Křivan, "Lyapunov functions for LotkaVolterra predator-prey models with optimal foraging behavior," Journal of Mathematical Biology, vol. 39, no. 6, pp. 493-517, 1999.

[17] M. Lesnoff, C. Corniaux, and P. Hiernaux, "Sensitivity analysis of the recovery dynamics of a cattle population following drought in the Sahel region," Ecological Modelling, vol. 232, pp. 28-39, 2012.

[18] F. Grandval, "Pastoralism in sub-Saharan Africa: know its advantages; understand its challenges, act for its sustainability," Food Sovereignty Briefs no. 5, Inter-Réseaux Développement Rural, 2012. 


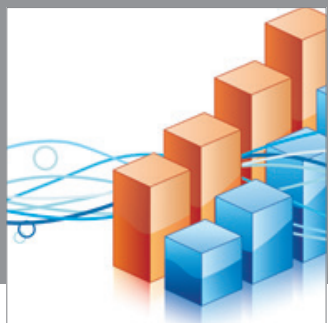

Advances in

Operations Research

mansans

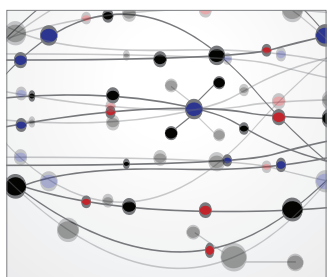

The Scientific World Journal
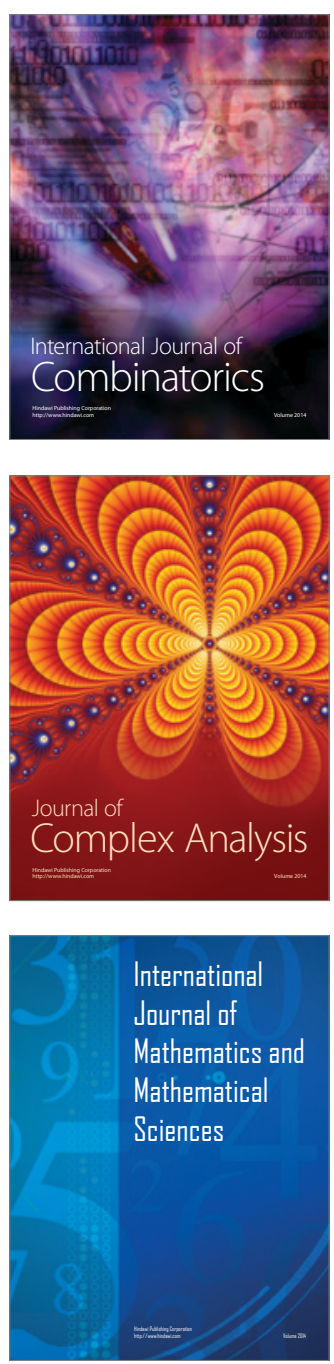
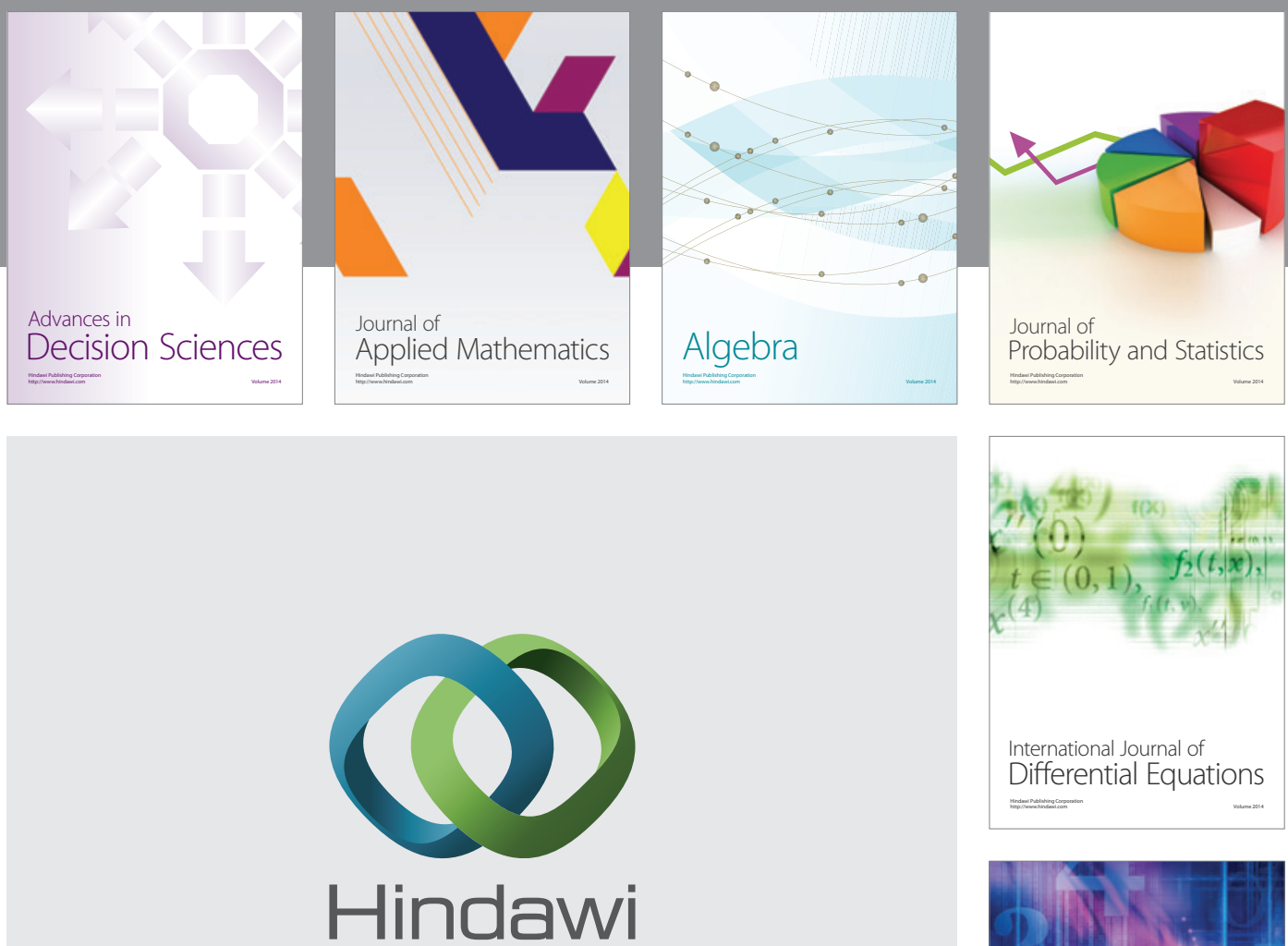

Submit your manuscripts at http://www.hindawi.com
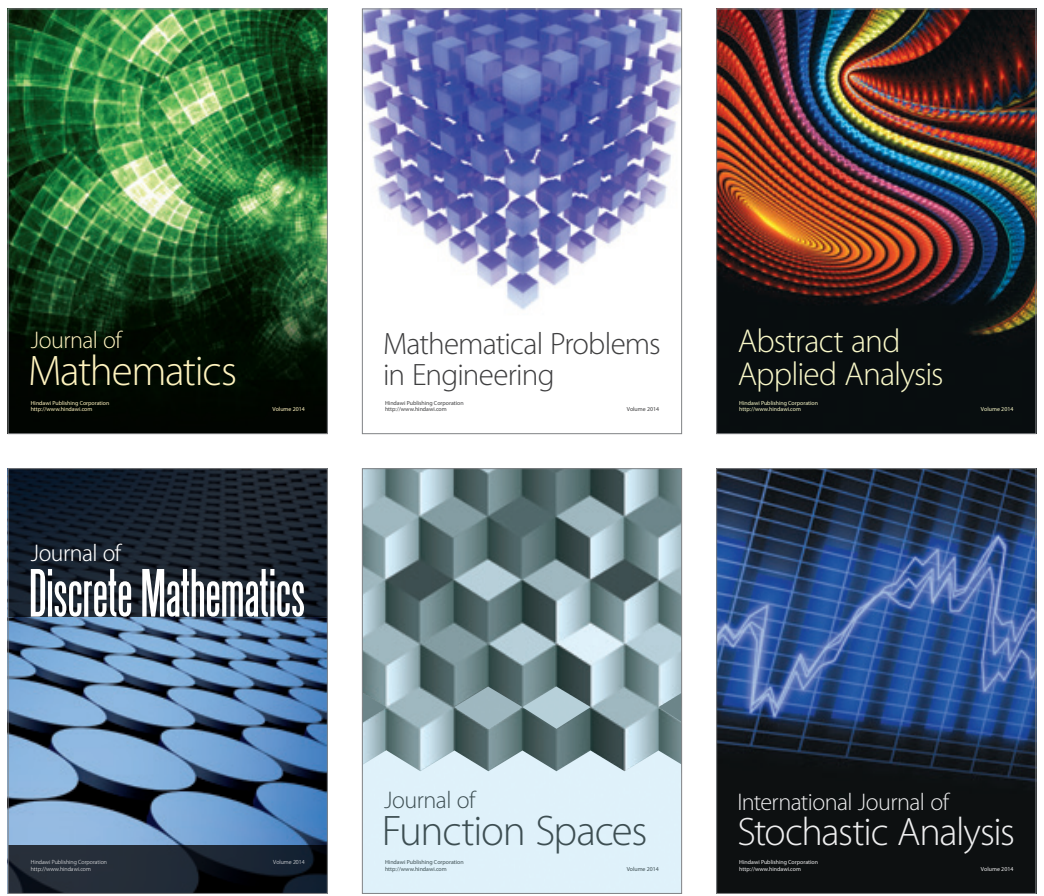

Journal of

Function Spaces

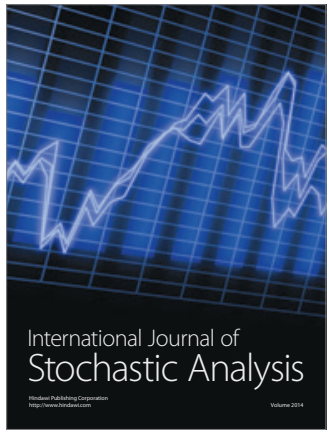

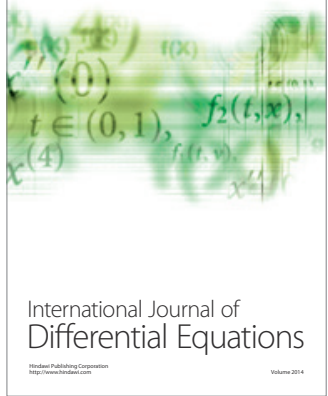
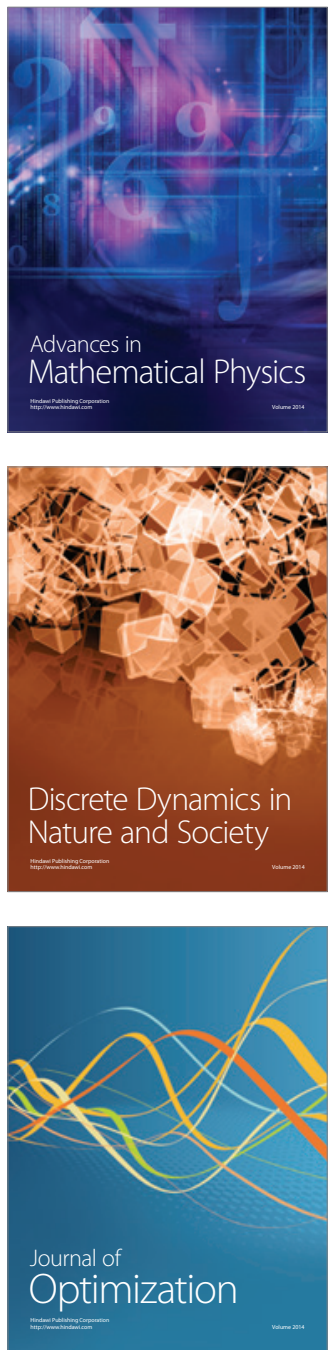